\title{
The Determination of Signs of Accelerated Ageing of Records made with Ballpoint Pen Inks by Using Chromatography Methods
}

\author{
Vitalijs Freidenfelds ${ }^{*}$, Certova $\mathrm{J}$ and Mekss $\mathrm{P}$
}

Department of Chemistry, University of Latvia, Latvia

"Corresponding author: Vitalijs Freidenfelds, Department of Chemistry, University of Latvia, Kr. Valdemāra Str. 48, Riga, Latvia, Tel: 902-491-8605; E-mail: vitalijs.freidenfelds@vteb.gov.lv

Received date: May 31, 2016; Accepted date: September 07, 2016; Published date: September 12, 2016

Copyright: (c) 2016 Freidenfelds V, et al. This is an open-access article distributed under the terms of the Creative Commons Attribution License, which permits unrestricted use, distribution, and reproduction in any medium, provided the original author and source are credited.

\begin{abstract}
A study of four different ballpoint pen inks was carried out using methods of HPLC and solid-phase micro extraction and gas chromatography mass spectrometry. Inks of different ballpoint pen manufacturers-two blue ones and two purple ones were chosen for the research.

Naturally aged ink samples on paper were stored under various conditions, and the comparative samples were exposed to aggressive influence of light, temperature and ozone. During the study of artificially and naturally aged samples differences in chemical composition of ink were identified-possible signs of accelerated ageing were detected in records and signatures that were made with blue and purple ballpoint pen inks.
\end{abstract}

Keywords: Ballpoint ink; 2-phenoxyethanol; Ink ageing; Artificial ageing; HPLC-MS; GC-MS; SPME; Forensic science; Questioned documents

Abbreviations: BV-3: Hexamethylated Basic Blue dye; BV-1: Pentamethylated Basic Violet dye; Tetra-BV: Tetramethylated Basic Violet dye; Tri-BV: Trimethylated Basic Violet dye; BV-11: Basic Violet 11 dye; BB-26: Basic Blue 26 dye; BB-26-der: Basic Blue 26 dye derivative.

\section{Introduction}

Characteristics of composition of ballpoint pen ink on paper are of great importance in determining the age and in a comparative study of documents in the forensic examination of documents and materials. The ink is characterized by using profiles of dyes and the research shows that the majority of inks have similar profiles. Given the fact that the ink composition includes colourless and volatile compounds, the use of the profile of the dyes in the study of ink is not enough. Also, without additional research and evaluation, stability and the ability of various dyes to degrade into other dyes undermines the objectivity of the results obtained only by studying the profile of dyes. Therefore, in assessing the ballpoint pen ink, both the initial profile of the ink and the data on possible transformations of substances in the ink, which can be caused by artificial ageing of the document, or under the influence of environmental factors, must be used. The signs of artificial ageing of the ink can be used not just in assessing the results of the sample, but also as evidence of aggressive physical and chemical action. The changes in the identified profile will make it possible to evaluate the causes of the changes - the result of chemical or physical impact. Presumably, the research results can also be used as criteria in the assessment of the sample during the determination of the age of the document. The research shows that volatile and non-volatile ink compounds can be efficiently analyzed by using the combined methods of chromatography and mass-spectrometry. The aim of the research was to determine the signs of the artificial ageing of ballpoint pen ink by using combined chromatographic methods.

\section{Experimental Method}

The analysis was carried out under the following conditions:

SPME-GC/MS: Shimadzu GC-2010 with Shimadzu GCMS-QP 2010 detector. Injector temperature $270^{\circ} \mathrm{C}$, column Restek RTX $1 \mathrm{MS} 30 \mathrm{~m}$ $\times 0.25 \mathrm{~mm} \times 0.25 \mu \mathrm{m}$, He $(113.7 \mathrm{~mL} / \mathrm{min}, 120.4 \mathrm{kPa})$. Split for fresh sample 1:50, split for degraded samples 1:20. Temperature program: $40^{\circ} \mathrm{C}$ to $230^{\circ} \mathrm{C}\left(15^{\circ} \mathrm{C} / \mathrm{min}\right) ; 230^{\circ} \mathrm{C}$ to $270^{\circ} \mathrm{C}\left(50^{\circ} \mathrm{C} / \mathrm{min}\right) ; 270^{\circ} \mathrm{C}(2 \mathrm{~min})$. Extraction was made with SPME 75/85 $\mu \mathrm{m}$ CAR/PDMS sorbent, 10 min in $1.5 \mathrm{~mL}$ chromatography vial in $200^{\circ} \mathrm{C}$.

HPLC/MS: Waters Alliance 2695 with Waters Quatro MicroTM API and MassLynx (Gas $\mathrm{N}_{2}$, flow $1 \mathrm{~mL} / \mathrm{min}$, positive polarity of ESI, voltage on the capillary $3 \mathrm{kV}$, voltage on cone $30 \mathrm{~V}$, temperature of the ion source $150^{\circ} \mathrm{C}$ ); Column Waters Symmetry ${ }^{\circ} \mathrm{C} 18,5 \mu \mathrm{m}, 4.6 \times 150$ $\mathrm{mm}$. Scan: $50 \mathrm{~m} / \mathrm{z}$ to $900 \mathrm{~m} / \mathrm{z}$. Extraction made in $200 \mu \mathrm{L}$ solution of mobile phase in ratio 1:1. Extracts are ultrasonicated for $30 \mathrm{~min}$.

Mobile phase: A- $0.01 \%$ formic acid ( $\mathrm{pH} 3$ ), Bacetonitrile;

Gradient: $20 \% \mathrm{~B}\left(\mathrm{t}_{0}\right) \rightarrow 40 \% \mathrm{~B}\left(\mathrm{t}_{1}=20 \mathrm{~min}\right) \rightarrow 100 \% \mathrm{~B}\left(\mathrm{t}_{2}=30 \mathrm{~min}\right) \rightarrow$ $20 \% \mathrm{~B}\left(\mathrm{t}_{3}=35 \mathrm{~min}\right) \rightarrow 20 \% \mathrm{~B}\left(\mathrm{t}_{3}=45 \mathrm{~min}\right)$.

\section{Naturally Aged Samples}

The sample $-15 \mathrm{~cm}$ straight line, performed with ballpoint pen ink using a ruler. Samples were applied to the white office paper (bleached, $80 \mathrm{~g} / \mathrm{m}^{2}$ ) which impact on the ageing processes was not examined in this study. Using each of the four pens, three sheets with samples were prepared and kept in the selected conditions:

- In a laboratory with sunlight access,

- In a laboratory without sunlight access, 
Citation: Freidenfelds V, Certova J, Mekss P (2016) The Determination of Signs of Accelerated Ageing of Records made with Ballpoint Pen Inks by Using Chromatography Methods. J Forensic Res 7: 337. doi:10.4172/2157-7145.1000337

Page 2 of 7

- Near an electro photographic device (Laser printer Kyocera KM-1635 KX).

A 2-year-old Cello Maxritter ink sample which was kept in the laboratory without sunlight access (in the dark) was used for the research. Two year old samples of other ballpoint pens were not available for the research.

\section{Description of the Process of Ageing}

Thermal degradation in an oven WDB Binder FD-53:

- Sample was gradually heated at $100^{\circ} \mathrm{C}$ for 5 days, an average of $8 \mathrm{~h}$ per day,

- Sample was heated at $160^{\circ} \mathrm{C}$ for $3 \mathrm{~h}$,
- Sample was heated at $200^{\circ} \mathrm{C}$ for $5 \mathrm{~min}$ and $40 \mathrm{~min}$.

- The oxidation of the samples : A sample was treated with ozone in a closed chamber for $3 \mathrm{hr}$. Ozone was generated using an electrostatic charger installation of Kjell Carlsson "Vacuum BoxModel IW" ( $8000 \mathrm{~V})$.

- Photo-degradation in machine Sun Test CPS +, Atlas MTT GMBH: A sample was placed in a closed chamber for the study of photostability and was irradiated for $3 \mathrm{~h}$ at room temperature (operating mode $\lambda$ from $320 \mathrm{~nm}$ to $800 \mathrm{~nm}, 2700 \mathrm{~kJ} / \mathrm{m}^{2}$ );

- A sample was placed in a closed chamber for the study of photostability and was irradiated for nine $9 \mathrm{~h}$ at room temperature (operating mode $\lambda$ from $320 \mathrm{~nm}$ to $800 \mathrm{~nm}, 8100 \mathrm{~kJ} / \mathrm{m}^{2}$ ).

\begin{tabular}{|c|c|c|c|c|c|c|c|c|c|c|c|c|}
\hline \multirow[b]{2}{*}{$\begin{array}{l}\text { Identified compound } \\
\text { in Cello Maxritter ink }\end{array}$} & \multicolumn{3}{|c|}{ Natural aged in laboratory } & \multicolumn{4}{|c|}{ Thermally degraded } & \multicolumn{3}{|l|}{ Photo degraded } & \multicolumn{2}{|c|}{$\mathrm{O}_{3}$ degraded } \\
\hline & $\begin{array}{l}\text { Fresh } \\
\text { sample }\end{array}$ & $\begin{array}{lr}6 & \text { month } \\
\text { (dark place) }\end{array}$ & $\begin{array}{l}2 \text { years } \\
\text { (dark } \\
\text { place) }\end{array}$ & $\begin{array}{l}100^{\circ} \mathrm{C} \\
40 \mathrm{~h}\end{array}$ & $\begin{array}{l}160^{\circ} \mathrm{C}, \\
3 \mathrm{~h}\end{array}$ & $\begin{array}{l}200^{\circ} \mathrm{C} \\
5 \mathrm{~min}\end{array}$ & $\begin{array}{l}200^{\circ} \mathrm{C}, \\
40 \mathrm{~min}\end{array}$ & $\begin{array}{ll}\begin{array}{l}\text { Natural: } \\
\text { months }\end{array} & \mathbf{6} \\
\text { (sunlight) } & \end{array}$ & $\begin{array}{l}\text { Artificia } \\
\text { I: } 3 \mathrm{~h}\end{array}$ & $\begin{array}{l}\text { Artificia } \\
\text { I: } 9 \mathrm{~h}\end{array}$ & $\begin{array}{l}\text { Natur } \\
\text { al }\end{array}$ & $\begin{array}{l}\text { Artificia } \\
\text { I: } 3 \mathrm{~h}\end{array}$ \\
\hline 2-Phenoxyethanol & $\sqrt{ }$ & $\sqrt{ }$ & $\sqrt{ }$ & $\sqrt{ }$ & $\sqrt{ }$ & $\sqrt{ }$ & $\sqrt{ }$ & $\sqrt{ }$ & $\sqrt{ }$ & $\sqrt{ }$ & $\sqrt{ }$ & $\sqrt{ }$ \\
\hline Benzyl alcohol & $\sqrt{ }$ & $\sqrt{ }$ & $\sqrt{ }$ & $\sqrt{ }$ & - & - & - & $\sqrt{ }$ & $\sqrt{ }$ & $\sqrt{ }$ & $\sqrt{ }$ & $\sqrt{ }$ \\
\hline Phenol & $\sqrt{ }$ & $\checkmark$ & - & - & - & - & - & $\sqrt{ }$ & $\sqrt{ }$ & $\checkmark$ & $\sqrt{ }$ & - \\
\hline Hexylen glycol & - & $\sqrt{ }$ & - & - & - & - & - & - & $\sqrt{ }$ & $\sqrt{ }$ & - & - \\
\hline $\begin{array}{l}\text { 2-(2-Ethoxyethoxy)- } \\
\text { ethanol }\end{array}$ & - & - & - & - & - & - & - & $\sqrt{ }$ & $\sqrt{ }$ & $\sqrt{ }$ & $\checkmark$ & - \\
\hline Benzaldehyde & $\sqrt{ }$ & $\sqrt{ }$ & V & $\sqrt{ }$ & - & - & - & $\sqrt{ }$ & $\sqrt{ }$ & $\sqrt{ }$ & $\sqrt{ }$ & $\sqrt{ }$ \\
\hline 2-Ethylhexanol & $\sqrt{ }$ & $\checkmark$ & - & - & - & - & - & $\sqrt{ }$ & $\sqrt{ }$ & $\checkmark$ & $\sqrt{ }$ & $\sqrt{ }$ \\
\hline 2-Ethylhexanal & - & $\checkmark$ & V & $\sqrt{ }$ & - & - & - & $\sqrt{ }$ & $\sqrt{ }$ & $\checkmark$ & $\sqrt{ }$ & $\sqrt{ }$ \\
\hline Acetophenone & - & - & - & - & - & - & - & $\sqrt{ }$ & - & - & - & - \\
\hline 2-Ethylhexane acid & - & - & - & - & - & - & - & $\sqrt{ }$ & - & - & - & - \\
\hline 1-Hydroxy-2-propanone & - & - & - & - & - & - & - & - & - & - & - & - \\
\hline Ethylene glycol & - & - & - & - & - & - & - & - & $\sqrt{ }$ & $\sqrt{ }$ & - & $\sqrt{ }$ \\
\hline 4-Dimethylaminophenol & - & - & - & - & - & - & - & - & $\sqrt{ }$ & $\sqrt{ }$ & - & - \\
\hline $\begin{array}{l}\text { 4-Hydroxy-4-methyl-2- } \\
\text { pentanone }\end{array}$ & - & - & - & - & - & - & - & - & - & - & - & $\sqrt{ }$ \\
\hline
\end{tabular}

Table 1: Results of the research of Cello Maxritter ink with SPME GC-MS.

\section{Ballpoint pen ink}

Inks of different ballpoint pen manufacturers-two blue ones (Schneider 105 and Mitsubishi Uni Jetstream) and two purples ones (Cello Maxritter and Deli Stationary No-6571) were chosen for the research.

\section{Results and Discussions}

Given the volume of received data and the similarity of the ageing process, further analysis is described based on the research of one ballpoint pen ink-Cello Maxritter. The results of the research conducted on Cello Maxritter ink by using solid-phase microextraction and gas chromatography - mass spectrometry is summarized in Table 1. The results show that 2-phenoxyethanol was detected in all the samples and benzyl alcohol in the majority of degraded and non-degraded Cello Maxritter samples. 2Phenoxyethanol can be detected even after high thermal impact. Benzyl alcohol is easily oxidized at room temperature to benzaldehyde, and then to benzene acid [1].

Similar tansformations also occur with 2-ethylhexanol-the alcohol is oxidized to 2-ethylhexanal and 2-ethylxehane acid respectively. 2Ethylhexanol is produced in samples aged both naturally and accelerated artificially and immediately partially oxidizes to 2ethylhexanal. After 2 years of natural ageing, and also 40-hour-long thermal influence $\left(100^{\circ} \mathrm{C}\right)$ 2-ethylhexanol is completely degraded to 2ethylhexanal. However, 2-ethylhexanal is completely degraded only as a result of natural ageing in the sunlight. The monomer of resin acetophenone was also found in these samples [2]. 
Citation: Freidenfelds V, Certova J, Mekss P (2016) The Determination of Signs of Accelerated Ageing of Records made with Ballpoint Pen Inks by Using Chromatography Methods. J Forensic Res 7: 337. doi:10.4172/2157-7145.1000337

Page 3 of 7

Considering the above, the presence of 2-ethylhexane acid and acetophenone in the samples can be used as a sign indicating the method of ageing - natural of artificial. In artificially aged samples there is 1-hydroxy-2-propanone that was not found in naturally aged samples. Presumably, the 1-hydroxy-2-propanone is a product of degradation of Michler's ketone [3].

As a result of artificial photodegradation of the samples, a similar profile of volatile compounds was produced. For example, in 3 and 9- hour-long aged samples ethyleneglycol and 4-(dimethylamino)-phenol were detected. Ethyleneglycol is probably produced as a result of partial degradation of 2-phenoxyethanol, but 4-(dimethylamino)phenol is produced as a result of degradation of dyes [4,5]. As a result of artificial photodegradation, hexylenglycol can also appear in the samples, but after 9- hour-long exposure $(320 \mathrm{~nm}$ to $800 \mathrm{~nm} ; 8100$ $\mathrm{kJ} / \mathrm{m}^{2}$ ) 4-hydroxy-methyl-2-pentanone can be produced.

\begin{tabular}{|c|c|c|c|c|c|c|c|c|}
\hline \multirow{2}{*}{ Sample (Degradation and conditions) } & \multicolumn{4}{|c|}{ Basic Violet } & \multicolumn{2}{|l|}{ Basic Blue } & \multirow{2}{*}{ BV-11 } & \multirow{2}{*}{ Michler's ketone } \\
\hline & BV-3 & BV-1 & Tetra-BV & Tri-BV & BB-26-der. & BB-26 & & \\
\hline \multicolumn{9}{|l|}{ Naturally aged } \\
\hline In the dark for 6 months & -13.1 & -24.1 & -30.9 & -51.9 & -6.13 & -1.14 & -100 & -30.5 \\
\hline "Natural" ozone for 6 months & -6.6 & -7.51 & -6 & -15 & 8.57 & -0.83 & -100 & -24.1 \\
\hline Exposed to sunlight & -95.8 & -91.9 & -86.1 & -65.9 & -68.7 & -88.5 & -100 & -100 \\
\hline In the dark for 2 years & -8.38 & -2.34 & 4.46 & 26.6 & 20.5 & -4.67 & -47.6 & 93.6 \\
\hline \multicolumn{9}{|l|}{ Thermally degraded } \\
\hline $100^{\circ} \mathrm{C}, 40 \mathrm{~h}$ & -2.1 & -2.01 & 8.45 & -12.9 & 20.6 & -12.6 & -100 & -43.5 \\
\hline $160^{\circ} \mathrm{C}, 3 \mathrm{~h}$ & -94.4 & -82.7 & -61.3 & -66 & -59.9 & -92.6 & -48 & -100 \\
\hline $200^{\circ} \mathrm{C}, 5 \mathrm{~min}$ & -95.2 & -94 & -82.7 & -62.2 & -81.8 & -84.3 & -100 & -89.6 \\
\hline $200^{\circ} \mathrm{C}, 40 \mathrm{~min}$ & -97.3 & -90.6 & -78.1 & -75.3 & -73.7 & -94.4 & -100 & -100 \\
\hline \multicolumn{9}{|l|}{ Photodegraded } \\
\hline $3 \mathrm{~h}(2700 \mathrm{~kJ} / \mathrm{m} 2)$ & -83.1 & -82.6 & -64.9 & 13.9 & 10.1 & -59.1 & -21.2 & -71.7 \\
\hline $9 \mathrm{~h}(8100 \mathrm{~kJ} / \mathrm{m} 2)$ & -93.8 & -85.5 & -60.6 & -44.4 & -60.6 & -83.2 & -61.1 & -72 \\
\hline \multicolumn{9}{|l|}{ Ozonized } \\
\hline $3 \mathrm{~h}$ in $\mathrm{O} 3$ chamber & -74.3 & -64.7 & -50 & -44.6 & -62.7 & -64.6 & -100 & -50.3 \\
\hline
\end{tabular}

Table 2: Results of the research of Cello Maxritter ink with HPLC-MS.

According to the information obtained (Table 2), the biggest increase in peak areas of different dyes is observed in the 2 year old sample-the peak of Mitchler's ketone increased, as well as Tetra-BV, Tri-BV and BB-26-der. dyes. Most likely, this is due to the lack of many degrading factors, which enables BV-3, BV-1 and BB-26 dyes to degrade "naturally", without a destruction of their degradation products (their amount in the samples increases).

In all samples of Cello Maxritter peak areas are different. For example:

- In naturally aged samples, except for the one aged in the sunlight, the peaks of dyes BV-3 and BV- $1<25 \%$ are decreased, while in all artificially aged samples, except for the one that was thermally aged for 40 hours, the areas of the dyes are reduced $>64 \%$,

- Michler's ketone, which is a product of degradation of the BV dye, was not been detected when the dye was degraded using the sunlight and in the case of two thermal degradations. In general, the greatest reduction in the area of the peak of ketone is observed in artificially aged samples.
Taking into account that the increase in the peak area of Michler's ketone for the 2 year old sample is $93.6 \%$, it can be concluded that if a sample is kept in an office or a laboratory (normal storage conditions) in the dark, this product of degradation is accumulated. Furthermore, aggressive natural or artificial sunlight impact can cause degradation of ketone [6].

The results of study of four different ballpoint pens showed similar trends of degradation but their numerical values differ.

Graphical relationship between the Basic Blue 26 dye and its derivative in different samples is shown in Figure 1.

The results show that two relative groups are formed:

- A group which includes the fresh sample, thermally degraded for $40 \mathrm{~h}$ and all naturally aged samples, except for the one aged in the open sunlight.

- A group which includes the sample that was aged naturally in the sunlight, and all artificially aged samples, except for that photo 
degraded for three hours and thermally degraded at $160^{\circ} \mathrm{C}$ for 40 h.

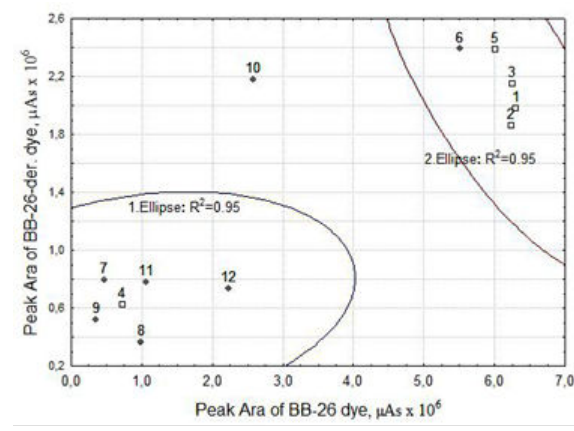

Figure 1: Graphical relationship between BB-26 dye and its derivatve (BB-26-der.) in the degraded samples of Cello Maxritter. $\square$ : represents naturally aged samples; $\bullet$ : artificially aged ones. 1 : a fresh sample; 2: a sample kept in the dark for 6 months; 3 : a sample exposed to "natural" ozone for 6 months; 4 : a sample exposed to sunlight; 5: a sample kept in the dark for 2 years; 6: a sample thermally degraded at $100^{\circ} \mathrm{C}$ for $40 \mathrm{~h}$; 7 : a sample thermally degraded at $160^{\circ} \mathrm{C}$ for $3 \mathrm{~h} ; 8$ : a sample thermally degraded at $200^{\circ} \mathrm{C}$ for $5 \mathrm{~min}$; 9: a sample thermally degraded at $200^{\circ} \mathrm{C}$ for $40 \mathrm{~min} ; 10$ : a sample photodegraded for $3 \mathrm{~h}\left(2700 \mathrm{~kJ} / \mathrm{m}^{2}\right)$; 11 : a sample photodegraded for $9 \mathrm{~h}\left(8100 \mathrm{~kJ} / \mathrm{m}^{2}\right)$; 12 : a sample ozonized for $3 \mathrm{~h}$.

As a result of analysis all the samples are divided into two groups with $\mathrm{R} 2=0.95$. The location of the sample photo degraded for three hours does not make it possible to include it to either of these groups.

The location of the sample which was aged naturally in the sunlight can be explained by the intensity of sun exposure which has aggressive natural impact. The proximity of the sample that was thermally aged for $40 \mathrm{~h}$ to naturally aged samples may be due to two factors, and therefore explained by two hypotheses:

Thermal stability of the dye: $100^{\circ} \mathrm{C}$ temperature exposure is not fatal for the studied dye inks.

The process of curing the ink: Repeated heating can cause hardening of the surface of the ink, which when re-heated makes access of molecular oxygen difficult; oxygen accelerates the ageing of dyes [7].

The results obtained show that it possible to distinguish samples kept in an office or laboratory from those treated artificially or aggressively. Taking into account that BV dyes can be degraded and are linked with each other by chemical transformations (e.g. Ndemethylation reactions) [4,5], a three-dimensional chart (3D) showing the relationship of peak areas of the dyes was made (Figure 2).

This chart proves that the samples are divided into the above mentioned groups: in the upper right-hand corner of the chart there are naturally aged samples, and in the lower left-hand corner there are artificially aged samples. Besides, significant linearity in twodimensional (2D) areas can be noticed: BV-3 and BV-1, BV-3 and Tetra-BV. In order to evaluate objectively the deviation from linearity, additional research is required. Obviously, the division into groups can be used for a thorough study of the process of ageing.

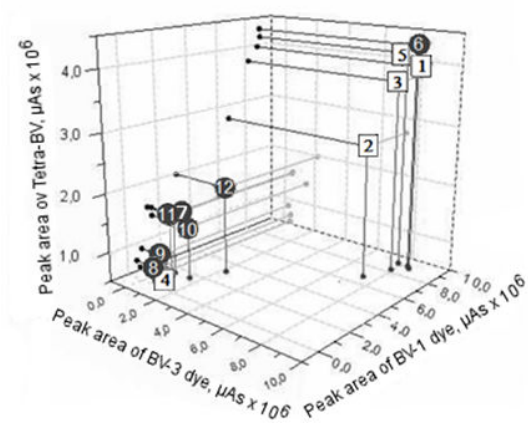

Figure 2: The graphical relationship between the BV-3 dye and its derivatives in degraded samples of Cello Maxritter ink. $\square$ : represents naturally aged samples; $\bullet$ : artificially aged ones; 1 : a fresh sample; 2 : a sample kept in the dark for 6 months; 3: a sample exposed to "natural" ozone for 6 months; 4: a sample exposed to sunlight; 5: a sample kept in the dark for 2 years; 6: a sample thermally degraded at $100^{\circ} \mathrm{C}$ for $40 \mathrm{~h} ; 7$ : a sample thermally degraded at $160^{\circ} \mathrm{C}$ for $3 \mathrm{~h}$; 8: a sample thermally degraded at $200^{\circ} \mathrm{C}$ for $5 \mathrm{~min}$; 9: a sample thermally degraded at $200^{\circ} \mathrm{C}$ for $40 \mathrm{~min}$; 10 : a sample photo degraded for $3 \mathrm{~h}\left(2700 \mathrm{~kJ} / \mathrm{m}_{2}\right)$; 11: a sample photo degraded for $9 \mathrm{~h}$ $\left(8100 \mathrm{~kJ} / \mathrm{m}_{2}\right) ; 12$ : a sample ozonized for $3 \mathrm{~h}$.

Without additional information about a sample graphic regularity between BB-26 dye and its derivative, as well as BV-3 and its derivatives, cannot be used as evidence of a type of degradation, as location in space depends on the amount of the sample in the extract. However, samples of the same size were used for the research, which makes it possible to judge objectively which group of degradation they belong to.

In order to prove that different methods of degradation belong to certain groups, analysis of changes in relations between dyes was made. The ratio of peak areas of BB-26 and BV-3 dyes and their derivatives is summarized in Table 3.

The relationship between peak areas of BB-26 and BB-26-der. practically does not change in naturally as well as artificially ozonized samples, but graphically they are in different groups (Figure 1). The same can be said about the 2-year-old sample and thermally aged for 5 min at $200^{\circ} \mathrm{C}$ samples. This shows that degradation of BB-26 and BB-26-der. dyes can take place while maintaining the proportion between the dyes, but their decay depends on the intensity of exposure.

Given that graphical relationship is valid only for the same size samples, material for studying ink records must be of the same size and morphology. The ratio of peak areas for the fresh sample BV-3/VB-1 is $1: 1,10$. Having compared these results with the results of Hofer's [8] research, it was found that Hofer [8] does not describe the case where the peak area of BV-3 is equal to or slightly less than the peak area of BV-1.

However, the results show that regardless of the method of degradation (artificial or natural), the peak area of BV-1 increases in comparison with BV-3. These results coincide with Hofer's [8] results when peak area of BV-3 is more than peak area of BV-1 in the fresh sample [8]. 
Citation: Freidenfelds V, Certova J, Mekss P (2016) The Determination of Signs of Accelerated Ageing of Records made with Ballpoint Pen Inks by Using Chromatography Methods. J Forensic Res 7: 337. doi:10.4172/2157-7145.1000337

Page 5 of 7

\begin{tabular}{|c|c|c|c|c|}
\hline \multirow{2}{*}{$\begin{array}{l}\text { Sample } \\
\text { (Degradation and conditions) }\end{array}$} & \multicolumn{4}{|c|}{ Ratio of peak areas } \\
\hline & $\mathrm{S}_{\mathrm{BB}-2 \mathrm{E}} / \mathrm{S}_{\mathrm{BB}-26-\mathrm{der}}$ & $\mathrm{S}_{\mathrm{BV}-3} / \mathrm{S}_{\mathrm{BV}-1}$ & $\mathbf{S}_{\mathrm{BV}-1} / \mathbf{S}_{\text {Tetra-BV }}$ & $\mathbf{S}_{\text {Tetra-BV }} \mathbf{S}_{\text {Tri-BV }}$ \\
\hline \multicolumn{5}{|l|}{ Naturally aged } \\
\hline Fresh & 3.18 & 0.94 & 2.25 & 5.09 \\
\hline In the dark for 6 months & 3.35 & 1.08 & 2.47 & 7.31 \\
\hline Exposed to "natural" ozone for 6 months & 2.91 & 0.95 & 2.22 & 5.62 \\
\hline Exposed to sunlight & 1.17 & 0.48 & 1.32 & 2.07 \\
\hline In the dark for 2 years & 2.52 & 0.85 & 2.21 & 4.20 \\
\hline \multicolumn{5}{|l|}{ Thermally degraded } \\
\hline $100^{\circ} \mathrm{C}, 40 \mathrm{~h}$ & 2.31 & 0.91 & 2.13 & 6.31 \\
\hline $160^{\circ} \mathrm{C}, 3 \mathrm{~h}$ & 0.59 & 0.31 & 1.01 & 5.79 \\
\hline $200^{\circ} \mathrm{C}, 5 \mathrm{~min}$ & 2.74 & 0.75 & 0.79 & 2.33 \\
\hline $200^{\circ} \mathrm{C}, 40 \mathrm{~min}$ & 0.67 & 0.27 & 0.97 & 4.50 \\
\hline \multicolumn{5}{|l|}{ Photodegraded } \\
\hline $3 \mathrm{~h}\left(2700 \mathrm{~kJ} / \mathrm{m}^{2}\right)$ & 1.18 & 0.92 & 1.12 & 1.57 \\
\hline $9 \mathrm{~h}\left(8100 \mathrm{~kJ} / \mathrm{m}^{2}\right)$ & 1.36 & 0.40 & 0.83 & 3.60 \\
\hline \multicolumn{5}{|l|}{ Ozonized } \\
\hline $3 \mathrm{~h}$ in chamber & 3.03 & 0.69 & 1.59 & 4.60 \\
\hline
\end{tabular}

Table 3: Ratio of peak areas of BB-26 and BB-26-der. dyes, BV-3 dye and its derivatives in aged samples of Cello Maxritter ink.

Based on numerical data in Table 3, a diagram showing ratio of area peaks of dyes was drawn in Figure 3: BV-3 and BV-1, BV-1 and tetra$\mathrm{BV}$, tetra-BV, and tri-BV.

The graph in Figure 3 confirms the earlier findings that samples of naturally aged inks can be distinguished from samples of artificially aged inks. The exceptions are the above-mentioned examples (numbers 6 and 4 on the graph). Also, the location of the ozonized sample and the sample that was photodegraded for $3 \mathrm{~h}$ is not pronounced.

During the research it was found that despite the differences in the profiles of volatile and non-volatile components of the inks, trends of ageing (degradation) are similar and in many respects the same because the study of 3 other inks gives similar results.

\section{Assessment of the Results of SPME GC-MS and HPLC- MS}

Thermal degradation leads to evaporation and decomposition of the components of ink. As a result, the number of volatile components in the test ink is reduced to 2. However, in cases of other types of degradation there is qualitative diversity of components. For example, in a 2-year-old sample of ballpoint pen Cello Maxritter ink four volatile components-2-phenoxyethanol, benzyl alcohol, benzaldehyde and 2-ethylhexanal were found. Thus, if ink peaks were not found in the chromatogram of a sample or only peak of 2-phenoxyethanol or benzyl alcohol (less often), it may prove aggressive thermal impact on the sample.
Residues of dyes were found only in artificially aged samples, photo degraded and ozonized. These products were not found in any naturally aged sample.

Residues of polymeric resin prove that Cello Maxritter and Deli Stationary no 6571 inks contain acetone-formaldehyde resin. When inks degrade, polymers are degraded to monomeric fragments which are volatile enough to be studied using the method of gas chromatography of mass-spectrometry (GC/MS). The above mentioned degradation was found only in the samples which were naturally aged in the sunlight. However, this sign (regularity) cannot be used as universal differentiative sign because monomers were not found in the samples which were naturally aged without sunlight; it is not possible to distinguish them from those aged differently if there are no additional signs.

In chromatograms of all artificially aged samples there are new peaks with different values of molecular ions. However, we could not identify them without additional research. For example, peaks with the value of molecular ion $\mathrm{m} / \mathrm{z}=401 \mathrm{might}$ be due to the derivative of Basic Violet 11 dye which is produced as a result of deamination. Peaks with the values of molecular ions $\mathrm{m} / \mathrm{z}=470$ and $\mathrm{m} / \mathrm{z}=456$ most probably belong to products of degradation of Basic Blue 26 when as a result of $\mathrm{N}$-demethylation reaction two groups $\mathrm{CH}_{3}$ removes.

In the profiles of inks having Basic Violet dye there are peaks with values of molecular ions $\mathrm{m} / \mathrm{z}=316$, which most probably belongs to demethylated Basic Violet dye and $\mathrm{m} / \mathrm{z}=302$, most probably belonging to monomethylated Basic Violet dye. 
Page 6 of 7

Fragments of dyes found with GC-MS could not be separated using HPLC-MS method because compounds are emitted in unconfined volume. This is accounted for the distinct polarity of amines and the structural similarity of these substances. In order to separate these substances, it is necessary to modify the chromatographic method which was used.

When thermal degradation takes place at $200^{\circ} \mathrm{C}$ for 40 min both ink and paper degrade. Ink is decolorized and paper turns yellow-brown and becomes brittle, dehydrated and perhaps cellulose is destroyed. When such samples were extracted it was found that thermally degraded samples are difficult to extract in solvents, the line of the sample does not become decolorized and the extract was not coloured enough. This can be accounted for the evaporation of the solvent during the thermal degradation, which influences solubility of ink and possible process of hardening of ink polymers and diffusion of dyes in deep layers of paper. Therefore, it is advisable to use other solvents or increase the extraction time and temperature.

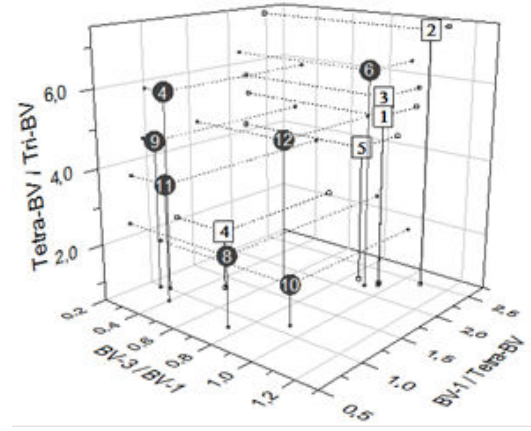

Figure 3: Graphical relationship between the ratios of peak areas of BV-3 dyes and its derivatives in degraded samples of Cello Maxritter ink.

1: a fresh sample; 2: a sample kept in the dark for 6 months; 3 : a sample exposed to "natural" ozone for 6 months; 4: a sample exposed to sunlight; 5 : a sample kept in the dark for 2 years; 6: a sample thermally degraded at $100^{\circ} \mathrm{C}$ for $40 \mathrm{~h} ; 7$ : a sample thermally degraded at $160^{\circ} \mathrm{C}$ for $3 \mathrm{~h} ; 8$ : a sample thermally degraded at $200^{\circ} \mathrm{C}$ for $5 \mathrm{~min}$; 9: a sample thermally degraded at $200^{\circ} \mathrm{C}$ for $40 \mathrm{~min}$; 10: a sample photodegraded for $3 \mathrm{~h}\left(2700 \mathrm{~kJ} / \mathrm{m}^{2}\right)$; 11 : a sample photodegraded for $9 \mathrm{~h}\left(8100 \mathrm{~kJ} / \mathrm{m}^{2}\right) ; 12$ : a sample ozonized for $3 \mathrm{~h}$.

Complex chromatographic studies of ink are more effective than the use of one method only because it makes it possible to obtain more signs for objective assessment of processes and changes. For example, having studied samples which were naturally aged in the sunlight with the help of HPLC-MS, we can conclude that the samples were subjected to aggressive influence, they were aged artificially. However, having studied a sample with the help of GC-MS, we can conclude that it was aged naturally as it contains substances characteristic of natural ageing (for example, monomers of polymers) and does not contain products of accelerated (artificial) degradation. The above facts mean that if we use both methods, we can make an objective conclusion in difficult cases, when a sample aged naturally but in more severe conditions.

Therefore, in order to determine whether there is a correlation between the degree of degradation of dyes and their decay products, it is advisable to study dyes using HPLC-MS method and compare the obtained results with the results of GC-MS.

Summarizing all the results, we can identify several most significant signs of accelerated (artificial) ageing of ink records.

\section{According to volatile components:}

- 2-Phenoxyethanol and/or benzyl alcohol are the only volatile substances in the profile of ink,

- There are no volatile components,

- There are products of decomposition of dyes in the profile of ink (residues of dyes),

- There is 1-hydroxy-2-propanone in the profile of violet ink,

- There are no monomers of polymers.

According to non-volatile components:

- The decrease in peak areas of dyes in chromatograms - Basic Violet 3 and Basic Violet 1, tetramethylated Basic Violet and trimethylated Basic Violet (information from database or collection is needed),

- Mickler's ketone is not accumulated; there is slight increase in its peak area (is determined experimentally),

- Reduced ability to be extracted (is determined when samples of the same size and the same distribution of ink are studied),

- Presence of new substances with $\mathrm{m} / \mathrm{z}=401, \mathrm{~m} / \mathrm{z}=484$ in the profile.

Taking into account that there might be linkage between the differences found during the research in artificially and naturally aged ink samples and the changes in the ability to be extracted and the fact that the extraction efficiency of differently aged samples was not checked, the results obtained can be considered reliable only in the complex of methods used and the conditions of the analysis. In order to use the signs described in expert practice it is necessary to use comparative samples (sample collection, if possible).

The findings are valid only for ink profiles used in the research and samples which are not older than six months and degraded in the above described conditions.

Taking into account the diversity of ink profiles and mechanisms of ageing, the established signs of accelerated (artificial) ageing can be used in expertise of documents only together with additional examination (for example, optical and microscope), because one sign is not enough to come to the conclusion that ageing was accelerated.

\section{Conclusion}

The combined method of solid-phase extraction gas chromatography - mass-spectrometry and high performance liquid chromatography can be used for analysis of volatile and non-volatile ink components to determine an abnormality in the standard composition.

In spite of the differences in composition of examined inks, tendencies of ageing are similar, which makes it possible to standardize the described methods and principles of analysis and use them in the study of inks.

Found signs are not reliably to distinguish artificial and accelerated natural ageing, but they may indicate that the document has been exposed to aggressive action. Such information may be useful for forensic experts in document dating, because it provides additional information about the storage conditions of the questioned document. 
Citation: Freidenfelds V, Certova J, Mekss P (2016) The Determination of Signs of Accelerated Ageing of Records made with Ballpoint Pen Inks by Using Chromatography Methods. J Forensic Res 7: 337. doi:10.4172/2157-7145.1000337

Page 7 of 7

Obtained data was not analyzed statistically as the only four pens were examined. However, the similarity of the results allows us to state that accumulation of degradation products can occur at slow ageing, but accelerated ageing can cause also ageing of breakdown product.

The HPLC-MS method appears most suitable for the study, as it allows analyzing substances which decomposition products are not volatile and can be detected for measuring abnormality in relations.

\section{Acknowledgement}

This work has been supported by the European Social Fund within the project, Support for Doctoral Studies at University of Latvia.

\section{References}

1. Hussein FH, Alkhateeb AN (2007) Photo-oxidation of benzyl alcohol under natural weathering conditions. Desalination. Desalination 209 350-355.

2. Bugler JH, Buchner H, Dallmayer A (2005) Characterization of ballpoint pen inks by thermal and desorption and gas chromatography-mass spectrometry. J Forensic Sci 50: 1209-1214.
3. Lu CS, Mai FD, Wu YC, Yao IC, Hsu PY, et al. (2009) Photocatalytic Degradation of Michler's Ketone in Water by UV Light Illumination Using $\mathrm{TiO} 2$ Photocatalyst: Identification of Intermediates and the Reaction Pathway. J Chi Chem Soc 56: 729-740.

4. Weyermann C, Kirsch D, Vera CC, Spengler B (2009) Evaluation of the photodegradation of crystal violet upon light exposure by mass spectrometric and spectroscopic methods. J Forensic Sci 54: 339-345.

5. Caine MA, McCabe RW, Wang L, Brown RG, Hepworth JD (2001) The Influence of Singlet Oxygen in the Fading of Carbonless Copy Paper Primary Dyes on Clays. Dyes Pigm 49: 135-143.

6. Confortin D, Neevel H, Brustolon M, Franco L, Kettelarij AJ, et al. (2010) Crystal violet: Study of the photo-fading of an early synthetic dye in aqueous solution and on paper with HPLC-PDA, LC-MS and FORS. J Phys Conf Ser 231: 012011.

7. Keuch P (2003) Effect of Auxochromes to the light absorption of Triphenylfarbstoffe . Berlin. University Regensburg pp: 27.

8. Hofer R (2004) Dating of ballpoint pen ink. J Forensic Sci 49: 1353-1357. 